\title{
Stroke caused auditory attention deficits in children
}

\author{
Acidente vascular cerebral causa défices da atenção seletiva auditiva em crianças \\ Karla Maria Ibraim da Freiria Elias, Maria Valeriana Leme de Moura-Ribeiro
}

\begin{abstract}
Objective: To verify the auditory selective attention in children with stroke. Methods: Dichotic tests of binaural separation (non-verbal and consonant-vowel) and binaural integration — digits and Staggered Spondaic Words Test (SSW) — were applied in 13 children (7 boys), from 7 to 16 years, with unilateral stroke confirmed by neurological examination and neuroimaging. Results: The attention performance showed significant differences in comparison to the control group in both kinds of tests. In the non-verbal test, identifications the ear opposite the lesion in the free recall stage was diminished and, in the following stages, a difficulty in directing attention was detected. In the consonant-vowel test, a modification in perceptual asymmetry and difficulty in focusing in the attended stages was found. In the digits and SSW tests, ipsilateral, contralateral and bilateral deficits were detected, depending on the characteristics of the lesions and demand of the task. Conclusion: Stroke caused auditory attention deficits when dealing with simultaneous sources of auditory information.
\end{abstract}

Key words: stroke, auditory perception, clinical outcome, infancy, childhood.

\section{RESUMO}

Objetivo: Verificar a habilidade de atenção seletiva em crianças com acidente vascular cerebral (AVC). Métodos: Foram aplicados testes dicóticos de separação (não verbal e consoante-vogal) e integração — dígitos e Staggered Spondaic Words Test (SSW) — binaural em 13 crianças (7 meninos), entre 7 e 16 anos, com AVC unilateral confirmado por neuroimagem. Resultados: 0 desempenho atencional diferiu entre os grupos na realização de ambos os tipos de tarefa. Ao teste não verbal, houve menor quantidade de identificações com a orelha contralateral à lesão em atenção livre e dificuldade de focalizar a atenção nas etapas direcionadas. No teste consoante-vogal, houve modificação da assimetria perceptual e dificuldade de focalizar a atenção nas etapas direcionadas. Nos testes de dígitos e SSW, foram constatados défices ipsilaterais, contralaterais e bilaterais dependendo das características da lesão e da demanda da tarefa. Conclusão: As crianças com AVC apresentaram défices na habilidade de atenção seletiva em presença de fontes simultâneas de informação auditiva verbal e não verbal.

Palavras-Chave: acidente vascular cerebral, percepção auditiva, infância.

The functional consequences of the stroke during infancy and childhood are considerably broad, involving motor, cognitive, sensory, behavioral, speech and language abilities ${ }^{1-5}$. With regard to auditory function, there are practically no data about stroke in children, although it is known that perception or processing may be compromised ${ }^{6}$.

The mechanisms and processes performed by the auditory system allow the recognition and interpretation of all kind of sounds. It encompasses a variety of abilities mediated by auditory centers located in the brainstem, the subcortex and the cortex, that could be affected by the stroke, causing deficits in auditory processing to some degree, even in patients whose evolution seems satisfactory. The aim of the present study was to assess the Central Auditory Processing (CAP) in children that had a favorable outcome after the vascular event. By analysing these cases, we wanted to verify if the stroke could cause a decrease in performance in any ear, which might collaborate for some difficulties in communication, learning and socialization, sometimes described in these children ${ }^{3,-9}$.

Of all the auditory abilities, selective attention seems to be the one with most relevance to the processing of stimuli in environments with unfavorable hearing conditions, such as parallel information or background noise ${ }^{10}$. This study applies dichotic verbal and non-verbal stimuli to evaluate the auditory selective attention in children affected by stroke when performing tasks related to binaural separation and integration.

Department of Neurology, Faculty of Medical Sciences, Universidade Estadual de Campinas (UNICAMP), Campinas, SP, Brazil.

Correspondence: Maria Valeriana Leme de Moura-Ribeiro; Departamento de Neurologia, Faculdade de Ciências Médicas, UNICAMP; Rua Tessália Vieira de Camargo 126 / Caixa Postal 6.111;13083-970 Campinas SP - Brasil; E-mail:valeriana@fcm.unicamp.br

Support: This work was supported by grants from the Conselho Nacional de Desenvolvimento Científico e Tecnológico (CNPq).

Conflict of interest: There is no conflict of interest to declare.

Received 13 April 2012; Received in final form 20 July 2012; Accepted 27 July 2012 


\section{METHODS}

The study was approved by the Ethic Research Committee of the Medical Sciences Faculty at the Universidade Estadual de Campinas, in accordance with the Regional Health Counsel's Resolution no 196/96 (Protocol no 372/2001). Parents signed the relevant consent form.

Thirteen children (seven boys) with unilateral stroke, between ages of 7 and 16 years, were evaluated. They were all right-handed before the vascular episode and/or presented a negative family history of left-handedness. They were all followed by a multidisciplinary team at the Childhood and Adolescence Stroke Research Group at Universidade Estadual de Campinas from the acute phase of the disease onwards. This group will be referred to as the study group (SG).

The stroke diagnosis was confirmed by clinical and neuroimaging investigations and, for the purposes of the study, the definition of the areas affected by the vascular lesion used the magnetic resonance as reference. This image was done up to six months before the auditory evaluation, and the scans were reviewed by a neuroradiologist.

The SG was matched with a control group (CG) consisting of 13 healthy, right-handed children, with matching age, sex and socio-economic level. In the match by age, a maximum difference of six months was permitted. The children in both groups went to regular public schools.

All participants had normal peripheral hearing, language and cognition abilities compatible with the tasks required by the CAP tests. These abilities were confirmed through multidisciplinary evaluations. The speech-language assessment was based on standardized tests using screening procedure and thematic images in spontaneous and semi-spontaneous conversation $^{11}$. The hearing assessment used standard baseline audiometric tests (pure-tone audiometry, speech audiometry, tympanometry, ipsilateral and contralateral acoustic reflex threshold). All children performed an inventory on auditory behavior and this questionnaire also was administered before CAP testing. The neuropsychological assessment included Luria-Nebraska, Wechsler Intelligence Scale for Children-WISC, Bender Visual Motor Gestalt test and the Test of School Performance.

The exclusion criteria were: bilateral stroke, recurrent vascular episodes, Moyamoya disease, sickle cell disease, epilepsy and psychiatric disorders. Children with impairments related to receptive or expressive language, auditory sensitivity, ossicular mobility in the middle ear and reflex responses to acoustic stimulation were also excluded, as well as those with an IQ below 70 .

\section{Evaluation of selective attention auditory ability}

The auditory evaluation occurred after the minimum period of six months following the stroke and consisted of the application of four CAP tests: non-verbal dichotic, consonant-vowel, dichotic digits and Staggered Spondaic Word test (SSW).

The first two tests aimed at the investigation of selective attention in binaural separation task. In this test, different stimuli are presented simultaneously to both ears, only one of which should be repeated (in the free recall, the child had to respond to the first item perceived and, in the subsequent stages, respond only to stimuli perceived by the specified ear - right or left) ${ }^{12}$.

The last other two tests evaluate selective attention in binaural integration task, so the children are asked to repeat, respectively, all stimuli presented simultaneously to both ears ${ }^{12}$.

These tests have normative values available for Brazilian Portuguese speakers ${ }^{12}$. All tests were applied in a soundtreated room, using a two-channel audiometer connected to a CD player - calibration standard ANSI-69. All test material was presented via TDH-39 earphones at a $50 \mathrm{~dB}$ sensation level, referenced to the pure-tone audiogram average (at 0.5, $1,2$ and $4 \mathrm{kHz})$.

Statistical analysis included analysis of variance (ANOVA) for repeated measures with conversion into ranks, profile test for contrasts and the Wilcoxon test for paired measurements with significance level of $5 \%(\mathrm{p}<0.05)$ and significant values marked with an asterisk.

\section{RESULTS}

The data for identification and unilateral structural brain impairment are presented in Table 1. The magnetic resonance scans of the brain revealed the involvement of the middle cerebral artery and its branches, anterior cerebral artery and vertebro-basilar system. Eight children were found to have impairments in the right hemisphere (Table 1).

At interview with parents, they were raised complaints referred to children's difficulty in attending promptly to calls, especially if engaged in other activities; difficulty in following oral instructions, requiring repetition of the messages; need to help to understand the topics taught in class and/or solve homework assignments; grades below average in one or more subjects, among others. In the CAP assessment, the average age in the SG was 11 years and 7 months, and in the CG, it was 11 years and 4 months. The auditory assessment for children in the SG was done approximately 5 years and 3 months after stroke.

Neuroimaging studies, conducted at follow up, confirmed the involvement of areas associated with central auditory processes, with lesions situated cortically in the left and right temporal and parietal lobes and/or subcortically in thalamus and/or basal ganglia and, in one patient, a mesencephalic lesion.

In the acute phase of the disease, the following were found: hemiplegia (11 children), difficulties in speech and 
Table 1. Stroke in children - identification data and cerebral impairment.

\begin{tabular}{|c|c|c|c|c|c|c|c|c|}
\hline Subject & Sex & Age SG/Stroke & Age SG/CAP & Age CG/CAP & Artery & Side & Type & Site \\
\hline S1 & $M$ & $7 y$ & $8 y$ & $8 y 5 m$ & MCA & $\mathrm{R}$ & 1 & Cortical-Subcortical \\
\hline S2 & $\mathrm{F}$ & $1 \mathrm{y} 1 \mathrm{~m}$ & $10 y 5 m$ & $10 y 6 \mathrm{~m}$ & MCA & $L$ & 1 & Subcortical \\
\hline S3 & M & $3 y$ & $12 y 9 \mathrm{~m}$ & $13 y 1 m$ & MCA & $\mathrm{R}$ & I & Subcortical \\
\hline S4 & $M$ & $5 y 4 m$ & $14 y 7 m$ & $14 y 7 m$ & MCA & L & I & Cortical-Subcortical \\
\hline S5 & $\mathrm{F}$ & $6 y 6 m$ & $16 y$ & $16 y 1 \mathrm{~m}$ & MCA & $\mathrm{R}$ & $\mathrm{I}-\mathrm{H}$ & Cortical-Subcortical \\
\hline S6 & M & $13 y 1 m$ & $16 y 7 m$ & $16 y 2 m$ & MCA/ACA & $\mathrm{R}$ & 1 & Cortical-Subcortical \\
\hline S7 & M & $3 y 8 m$ & $7 y 8 m$ & $7 y 3 m$ & MCA & $\mathrm{R}$ & $\mathrm{I}-\mathrm{H}$ & Cortical-Subcortical \\
\hline S8 & M & $4 y 11 \mathrm{~m}$ & $12 y 3 m$ & $11 y 10 \mathrm{~m}$ & MCA & $\mathrm{R}$ & 1 & Cortical \\
\hline S9 & $\mathrm{F}$ & $6 y 1 \mathrm{~m}$ & $10 y 6 m$ & $10 y 11 \mathrm{~m}$ & VB & $\mathrm{R}$ & $\mathrm{H}$ & Midbrain \\
\hline S10 & F & $10 y 0 \mathrm{~m}$ & $14 y 6 \mathrm{~m}$ & $14 y 2 m$ & MCA & L & । & Subcortical \\
\hline S11 & $\mathrm{F}$ & $7 y 5 m$ & $13 y 2 m$ & $12 y 8 m$ & ACA & L & $\mathrm{I}-\mathrm{H}$ & Cortical-Subcortical \\
\hline S12 & $\mathrm{F}$ & $10 y 6 \mathrm{~m}$ & $15 y$ & $15 y 2 m$ & MCA & $\mathrm{R}$ & 1 & Subcortical \\
\hline S13 & M & $4 \mathrm{y} 10 \mathrm{~m}$ & $8 y 1 \mathrm{~m}$ & $8 y 7 m$ & MCA/ACA & $\mathrm{L}$ & $\mathrm{I}-\mathrm{H}$ & Cortical-Subcortical \\
\hline
\end{tabular}

SG: study group; CG: control group; S: subject; M: male; F: female; y: years; m: months; MCA: middle cerebral artery; ACA: anterior cerebral artery; VB: vertebralbasilar system; R: right; L: left; I: ischemic; I-H: secondary hemorrhagic conversion of ischemia; H: hemorrhagic; Age SG/Stroke: age at time of stroke; Age SG/CAP: age at auditory assessment; Age CG/CAP: control group's age at auditory assessment.

language ( 5 children) and alterations in vision and/or behavior. Motor abnormalities persisted in most children. In regard to speech and language abilities, only one patient, S4, lacked fluency; the rest evolved favorably (Table 2).

The results, in absolute values, of SG and CG for the dichotic tests applied were included in Table 3.

In the non-verbal dichotic test, differences between the groups were not identified in relation to free recall. However, at this stage of the evaluation, the SG had fewer correct responses when the ear with direct access to the injured hemisphere was tested; in contrast, the CG had a similar amount of correct responses for each ear (Table 3).

In the stage to measure attention in the right ear, the SG scored significantly lower than the GC in the identification of stimuli presented in the target ear $\left(\mathrm{p}=0.0254^{*}\right)$, Wilcoxon (Fig 1). In the stage to measure attention in the left ear, there was no difference between the groups. The children in the CG performed on a level compatible with the established range for their age.

When the groups were compared in the consonant-vowel test of the free recall stage, children in the SG had inferior performance $\left(\mathrm{p}=0.0001^{*}\right)$, ANOVA.

At this stage of the test, it was also checked whether there was a difference in the number of identifications made with one of the ears, either right or left. It was found that in the SG there was no difference between ears in the ability to identify items (Table 3). However, in the CG, there was a significant amount of identification of the items presented in the right ear, a condition called right perceptual asymmetry or right ear advantage $\left(\mathrm{p}<0.0001^{*}\right)$.

In the focused attention stage, the SG showed inferior performance, with $\mathrm{p}=0.0001^{*}$ and $\mathrm{p}=0.0059^{*}$ (Wilcoxon) respectively for the right and left conditions of the test (Fig 2).

In the dichotic digits test, children in the SG showed deficits contralateral to the lesion (S1, S4, S7 and S15), ipsilateral (S5) or bilateral (S9 and S11) in the identification of the items presented (Table 3).
Table 2. Stroke in children - neuroimage and clinical manifestations of acute and chronic phases.

\begin{tabular}{|c|c|c|c|}
\hline \multirow{2}{*}{ Subject } & \multirow{2}{*}{$\begin{array}{l}\text { Magnetic } \\
\text { resonance }\end{array}$} & \multicolumn{2}{|c|}{ Evolution } \\
\hline & & Acute phase & Chronic phase \\
\hline \multirow[t]{2}{*}{ S1 } & $\begin{array}{l}\text { PR IFG I STG } \\
\text { PrCG SPG CR }\end{array}$ & Hemiplegia & Hemiparesis \\
\hline & LN CN IC & & \\
\hline \multirow[t]{2}{*}{ S2 } & Pt & Hemiplegia & $\begin{array}{l}\text { No residual } \\
\text { impairment* }\end{array}$ \\
\hline & & $\begin{array}{l}\text { Behavior } \\
\text { disorder }\end{array}$ & \\
\hline S3 & TLN CN IC & Hemiplegia & $\begin{array}{l}\text { No residual } \\
\text { impairment* }\end{array}$ \\
\hline S4 & FTP LN CN Cl & $\begin{array}{c}\text { Hemiplegia } \\
\text { Aphasia }\end{array}$ & $\begin{array}{c}\text { Hemiparesis } \\
\text { Speech disorder }\end{array}$ \\
\hline S5 & TP & Hemiplegia & $\begin{array}{l}\text { No residual } \\
\text { impairment* }\end{array}$ \\
\hline S6 & $\mathrm{TP}$ & Hemiplegia & $\begin{array}{l}\text { No residual } \\
\text { impairment* }\end{array}$ \\
\hline S7 & $\begin{array}{c}\text { PrCG SFG } \\
\text { MFG } \\
\text { CSO IIC CN } \\
\text { LN }\end{array}$ & $\begin{array}{l}\text { Speech } \\
\text { disorder }\end{array}$ & $\begin{array}{l}\text { No residual } \\
\text { impairment* }\end{array}$ \\
\hline S8 & SP & $\begin{array}{l}\text { Hemiplegia } \\
\text { Dysarthria }\end{array}$ & Hemiparesis \\
\hline S9 & InC SC & $\begin{array}{c}\text { Ptosis } \\
\text { Visual deficit }\end{array}$ & Visual deficit \\
\hline S10 & LN CN EC IC & $\begin{array}{c}\text { Hemiplegia } \\
\text { Aphasia }\end{array}$ & Hemiparesis \\
\hline S11 & $\begin{array}{l}\text { SoMG CG } \\
\text { CNICT }\end{array}$ & $\begin{array}{c}\text { Hemiplegia } \\
\text { Behavior } \\
\text { disorder }\end{array}$ & $\begin{array}{l}\text { Behavior disorder } \\
\text { Learning difficulty }\end{array}$ \\
\hline S12 & IC & Hemiplegia & $\begin{array}{l}\text { No residual } \\
\text { impairment* }\end{array}$ \\
\hline \multirow[t]{2}{*}{ S13 } & $\begin{array}{l}\text { LOG IFG PO P } \\
\text { MTG STG }\end{array}$ & Hemiplegia & Hemiparesis \\
\hline & $\begin{array}{c}\text { PhG I LN CN } \\
\text { EC IC }\end{array}$ & Aphasia & \\
\hline
\end{tabular}

S: subject; CG: cingulate gyrus; CN: caudate nucleus; CR: corona radiata; CSO: centrum semiovale; EC: external capsule; FTP: fronto-temporoparietal; I: insula; IC: internal capsule; InC: inferior colliculus; IFG: inferior frontal gyrus; LN: lenticular nucleus;LOG:Lateral orbital gyrus;MFG:middle frontal gyrus;MTG:middle temporal gyrus; P: parietal; Pt: putamen;PCG: postcentral gyrus;PrCG: precentral gyrus; PhG: parahippocampal gyrus; PO: pars opercularis; PR: perisylvian region; SC: superior colliculus; SFG: superior frontal gyrus; SoMG: superior orbitary medial gyrus; SP: superior parietal; STG: superior temporal gyrus; T: thalamus; TP: temporoparietal. * No residual impairments in physical and cognitive aspects of outcome. 


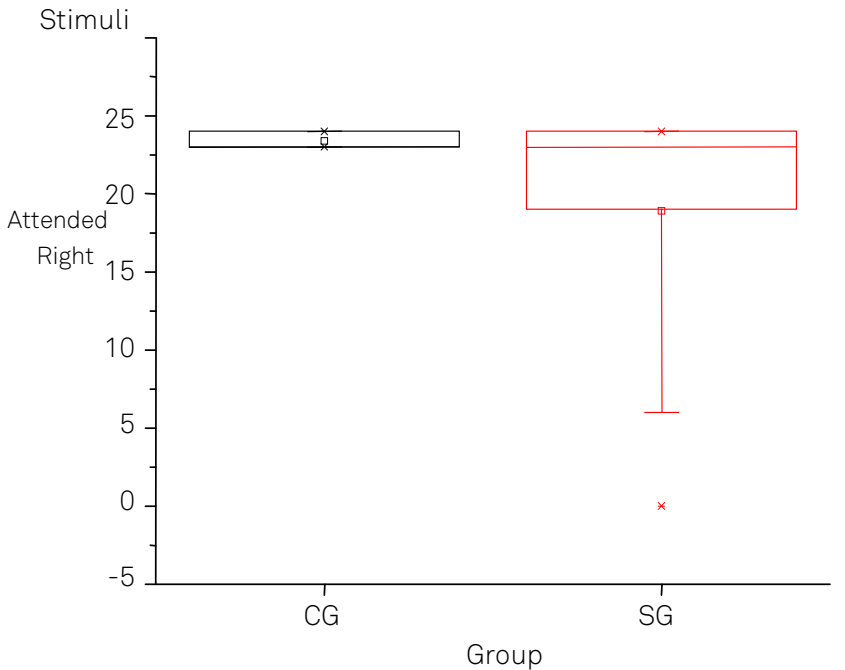

SG: study group; CG: control group.

Fig 1. Dichotic non-verbal - study group and control group performances at attended right condition.
Children in both groups showed differences in competence for binaural integration tasks $\left(\mathrm{p}=0.0038^{*}\right)$ (ANOVA). In the profile test for contrasts, considering the performance of both ears in each group, no differences were found; both in the SG and in the CG the number of identifications per ear did not vary. In the same test, when comparing the performance of both groups, the SG's performance was below the CG regardless of the ear. We found a difference for the right ear with $\mathrm{p}=0.0048^{*}$ and for the left ear, $\mathrm{p}=0.0311$ * was obtained (Fig 3).

In the SSW test, in relation to laterality of lesion, they were found contralateral (S1, S7, S11 and S13), ipsilateral (S4) and bilateral (S4, S8, S9 and S10) changes (Table 3).

In this test, a significant difference of $\mathrm{p}<0.0001^{*}$, ANOVA, was found. In the profile test for contrasts, when comparing the conditions within each group, it was found that in the SG there was no difference between right and left competitive conditions. In the $\mathrm{CG}$, the right was significantly superior to the left, with $\mathrm{p}=0.0056^{*}$, ANOVA. In the same test, when

Table 3. Dichotic tests - individual results in absolutes values.

\begin{tabular}{|c|c|c|c|c|c|c|c|c|c|c|c|c|c|c|c|c|}
\hline \multirow{3}{*}{ Subject } & \multicolumn{6}{|c|}{ Dichotic Non-verbal Test } & \multicolumn{6}{|c|}{ Consonant-Vowel Test } & \multirow{2}{*}{\multicolumn{2}{|c|}{$\begin{array}{c}\text { Dichotic } \\
\text { Digits } \\
(\%)\end{array}$}} & \multirow{2}{*}{\multicolumn{2}{|c|}{$\begin{array}{l}\text { SSW } \\
(\%)\end{array}$}} \\
\hline & \multicolumn{2}{|c|}{$\begin{array}{c}\text { Free } \\
\text { attention }\end{array}$} & \multicolumn{2}{|c|}{$\begin{array}{l}\text { Right } \\
\text { condition }\end{array}$} & \multicolumn{2}{|c|}{ Left condition } & \multicolumn{2}{|c|}{$\begin{array}{c}\text { Free } \\
\text { attention }\end{array}$} & \multicolumn{2}{|c|}{$\begin{array}{l}\text { Right } \\
\text { condition }\end{array}$} & \multicolumn{2}{|c|}{ Left condition } & & & & \\
\hline & $\mathrm{RE}$ & LE & RE & LE & $\mathrm{RE}$ & LE & $\mathrm{RE}$ & LE & $\mathrm{RE}$ & LE & $\mathrm{RE}$ & LE & $\mathrm{RE}$ & LE & $\mathrm{RC}$ & LC \\
\hline S1 & 14 & 8 & 19 & 1 & 2 & 19 & 18 & 2 & 20 & 1 & 12 & 1 & 93 & 78 & 80 & 58 \\
\hline $\mathrm{C} 1$ & 12 & 11 & 23 & 0 & 1 & 23 & 14 & 7 & 18 & 4 & 9 & 13 & 95 & 93 & 93 & 88 \\
\hline S2 & 13 & 11 & 24 & 0 & 0 & 24 & 10 & 9 & 17 & 3 & 8 & 12 & 100 & 98 & 98 & 98 \\
\hline $\mathrm{C} 2$ & 13 & 10 & 23 & 1 & 1 & 23 & 18 & 5 & 20 & 4 & 8 & 15 & 100 & 100 & 100 & 98 \\
\hline S3 & 13 & 9 & 20 & 2 & 0 & 23 & 15 & 4 & 13 & 6 & 14 & 7 & 100 & 98 & 93 & 90 \\
\hline C3 & 13 & 10 & 24 & 0 & 0 & 24 & 17 & 6 & 20 & 4 & 7 & 16 & 100 & 100 & 98 & 90 \\
\hline S4 & 12 & 12 & 23 & 0 & 0 & 24 & 11 & 9 & 12 & 9 & 10 & 9 & 93 & 98 & 85 & 88 \\
\hline C4 & 13 & 11 & 24 & 0 & 1 & 23 & 18 & 5 & 20 & 4 & 8 & 15 & 98 & 98 & 100 & 95 \\
\hline S5 & 6 & 18 & 21 & 2 & 1 & 23 & 11 & 9 & 10 & 9 & 10 & 10 & 93 & 95 & 78 & 90 \\
\hline C5 & 12 & 12 & 23 & 1 & 1 & 23 & 18 & 2 & 20 & 4 & 5 & 18 & 100 & 100 & 100 & 100 \\
\hline S6 & 11 & 13 & 24 & 0 & 0 & 24 & 12 & 8 & 11 & 9 & 13 & 8 & 100 & 98 & 100 & 100 \\
\hline C6 & 11 & 13 & 23 & 1 & 1 & 23 & 12 & 9 & 18 & 6 & 6 & 17 & 100 & 98 & 100 & 93 \\
\hline S7 & 0 & 0 & 0 & 0 & 0 & 0 & 15 & 5 & $\star$ & * & $\star$ & $\star$ & 100 & 20 & 80 & 18 \\
\hline C7 & 14 & 10 & 23 & 0 & 1 & 22 & 14 & 8 & $\star$ & $\star$ & $\star$ & * & 100 & 93 & 88 & 88 \\
\hline S8 & 13 & 11 & 23 & 1 & 0 & 24 & 12 & 5 & 8 & 9 & 11 & 7 & 93 & 98 & 85 & 78 \\
\hline C8 & 12 & 11 & 24 & 0 & 0 & 24 & 15 & 5 & 17 & 5 & 9 & 10 & 100 & 100 & 98 & 93 \\
\hline s9 & 12 & 10 & 24 & 0 & 0 & 24 & 12 & 8 & 14 & 5 & 11 & 10 & 93 & 73 & 78 & 78 \\
\hline C9 & 11 & 13 & 23 & 1 & 1 & 23 & 16 & 7 & 18 & 3 & 8 & 14 & 98 & 100 & 93 & 95 \\
\hline S10 & 11 & 13 & 24 & 0 & 0 & 23 & 11 & 11 & 10 & 8 & 8 & 12 & 98 & 95 & 78 & 85 \\
\hline C10 & 12 & 11 & 24 & 0 & 1 & 23 & 18 & 4 & 20 & 3 & 9 & 13 & 100 & 98 & 98 & 98 \\
\hline $\mathrm{S} 11$ & 10 & 13 & 15 & 9 & 2 & 22 & 4 & 13 & 4 & 13 & 3 & 15 & 83 & 83 & 68 & 95 \\
\hline C11 & 13 & 11 & 23 & 1 & 0 & 24 & 20 & 4 & 23 & 1 & 9 & 15 & 100 & 100 & 98 & 93 \\
\hline $\mathrm{S} 12$ & 13 & 11 & 23 & 1 & 0 & 24 & 11 & 7 & 16 & 4 & 4 & 14 & 100 & 95 & 95 & 93 \\
\hline C12 & 13 & 11 & 24 & 0 & 0 & 24 & 18 & 2 & 22 & 0 & 6 & 15 & 100 & 100 & 98 & 93 \\
\hline $\mathrm{S} 13$ & 7 & 17 & 6 & 17 & 7 & 15 & 3 & 20 & 1 & 19 & 1 & 16 & 23 & 100 & 3 & 83 \\
\hline C13 & 11 & 12 & 23 & 0 & 1 & 23 & 15 & 7 & 17 & 6 & 8 & 13 & 95 & 90 & 93 & 93 \\
\hline
\end{tabular}

SSW: staggered spondaic words test; S: subject; C: control; RE: right ear; LE: left ear; * not assess. 


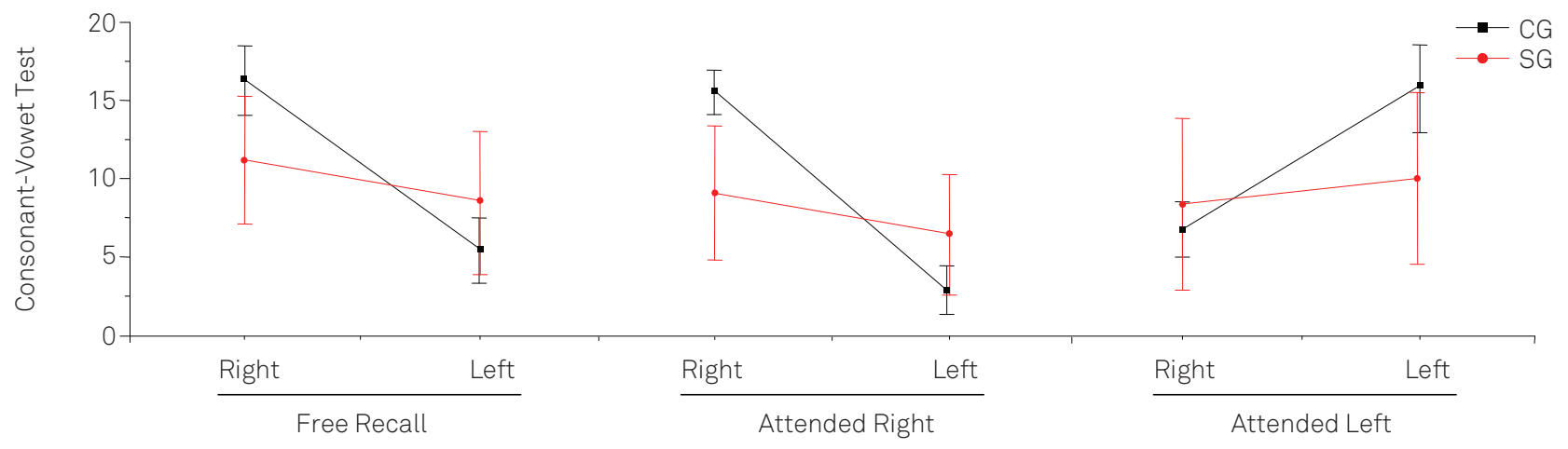

SG: study group;CG: control group.

Fig 2. Consonant-vowel - study group and control group performances in free recall, attended right, attended left conditions.

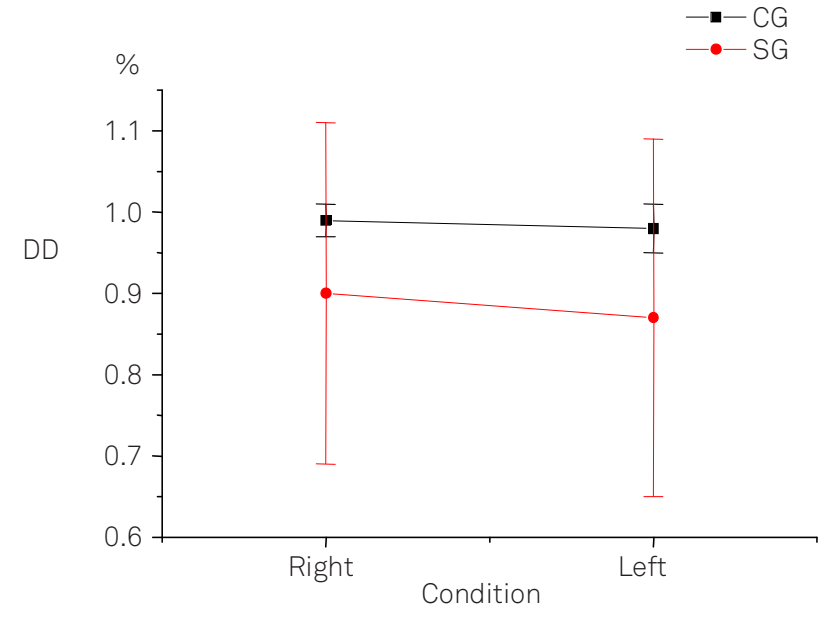

DD: Dichotic digits; SG: study group; CG: control group.

Fig 3. Dichotic digits - study group and control group performances in right and left competitive conditions.

comparing the groups, the SG performance was significantly lower than the $\mathrm{CG}$ in both competitive conditions, the right having $\mathrm{p}=0.0001^{*}$ and the left, $\mathrm{p}=0.0271^{*}$ (Fig 4).

\section{DISCUSSION}

In the present study, patients with stroke presented predominantly with ischemic lesions of the middle cerebral artery and cortico-subcortical involvement. In pediatric stroke, the involvement of the middle cerebral artery and its lenticular branches are the most commonly reported ${ }^{13-19}$ and, considering the course and distribution, there could cause alterations in blood flow of primary and secondary areas and others related to the processing and integration of auditory information. In one of the patients, S9, the lesion was mesencephalic. However, the affected structure, the inferior colliculus is required for the processing of complex stimuli due to the way in which it processes information ${ }^{10}$. Also because

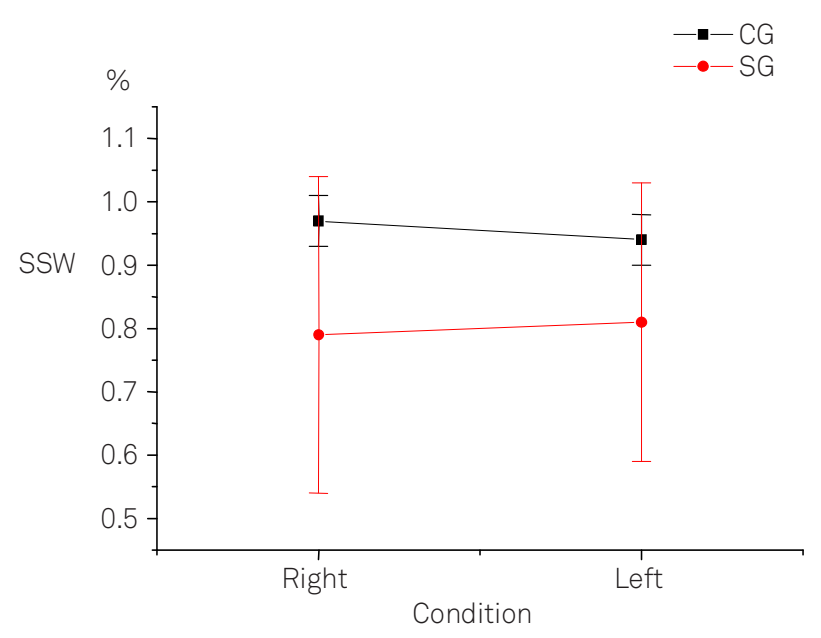

SSW: staggered spondaic words test; SG: study group; CG: control group.

Fig 4. Staggered Spondaic Words test - study group and control group performances in right and left competitive conditions.

of the complexity of its interaction, the inferior colliculus has profound implications for binaural abilities, notably for selective attention ${ }^{10}$.

The type of lesion (ischemic, ischemic with secondary hemorrhagic transformations and hemorrhage) is frequently associated at functional outcome, sometimes influencing physical and cognitive abilities in a wide spectrum, however this aspect did not make any difference within the SG. These children were evaluated in the chronic phase of the disease, presenting stability from a neurological point of view, good cognitive performance and displaying maintenance or recovery of linguistic ability. The requirement that these abilities be intact was a limiting factor for the number of patients in the study. Sequelae are generally common and intense in stroke patients, as shown in the literature ${ }^{1-5}$.

In the free recall stage of the dichotic non-verbal test, the SG identified more items with one ear than the other. This is a lateralization effect and it is a reduction in the amount of identifications made with the contralateral ear 
to the affected hemisphere, since most of the stimuli becomes lateralized to the ear with direct access to the intact hemisphere, in accordance with the paradigm of dichotic listening ${ }^{10,20}$. In situations in which there was competition, the information carried by the ipsilateral auditory pathway was suppressed by the contralateral pathway, which is more strongly represented. Historically, the combination of hemispheric specialization and contralateral dominance would justify the advantages of one ear over another, depending on the type of stimulus used, verbal or non-verbal ${ }^{10,20-21}$. In this stage, in normal people, symmetry between the ears is expected as a result of the contribution of the two cerebral hemispheres in the identification of this specific type of stimuli ${ }^{10,13,22}$, as was the case found in the CG. In the directed attention stages of the dichotic non-verbal test, the SG made more correct identifications with the ear requested, however, without reaching the amount of identifications expected for their age. The errors detected indicate that, although the subjects of the SG used the requested ear, the difficulty to recognize auditory information was the same or worse. This fact can be interpreted as a modification in the ability for directed attention in children with stroke.

In the consonant-vowel test, the finding of a right perceptual asymmetry ${ }^{10,14-15}$ is expected, since the stimuli presented to this ear have direct and quick access to the dominant hemisphere for language. In this test, children with lesions in the right hemisphere had an advantage with the right ear, but on a lesser magnitude compared to the children in the CG. The decreased right advantage in the SG can conceivably be explained by the processing of the stimuli, which essentially depends on the left hemisphere, but also requires the assistance of the right hemisphere. Considering that the stimuli are syllables, correct identification requires the extraction of acoustic parameters (frequency, duration, etc.), a capacity attributed to the right hemisphere ${ }^{10,20}$. In children with a lesion in the left hemisphere, the perceptual asymmetry took a different direction: right ear advantage, left ear advantage or symmetry between the ears. This is generally related to a reorganization of language after the vascular event ${ }^{23-26}$. These differences in degree and functional pattern are due to the interaction of multiple factors, including the localization, extent and type of injury, age at onset, epilepsy and integrity of surrounding and contralateral brain areas ${ }^{2,24-26}$. Usually, lesions involving the anterior and posterior temporal lobe result in inter-hemispheric reorganization and consequent reversal of dichotic verbal asymmetry, as seen in S13. Small perisylvian lesions can be followed by intra-hemispheric reorganization, and thus the right ear advantage is maintained ${ }^{24,25}$. In some patients in the SG, these areas were spared and, in these, attenuation or even reversal of the right ear advantage could be a result of the reorganization of subcortical auditory structures, or changes in subsequent stages of cortical processing $^{27,28}$. In focused attention, the SG had difficulty responding to stimuli in the two evaluation conditions, differing consistently from the CG. This is because the individuals in the SG, in the majority and independent of the side in which the lesion was located, failed to efficiently alter the focus of attention. The amount of errors and inversions made by the SG indicate that, in evolution, children with stroke were not able to use the required auditory canal, nor were they effective in suppressing the information received with the other ear.

In the two tests of binaural integration, dichotic digits and SSW, the SG had a decrease in the number of correct identifications with both ears, attributed to ipsilateral, contralateral and bilateral alterations. In general, deficits are observed in the ear contralateral to the affected hemisphere, as identified in three of our patients in the dichotic digits, and in four in the SSW. However, variable results are observed depending on the location and extent of the le$\operatorname{sion}^{10,25}$. Ipsilateral deficits may be related to deep parietal lesions or parieto-occipital lesions of either hemisphere when they affect the inter-hemispheric auditory fibers ${ }^{20}$, as noted in one of patients of this study who had ipsilateral deficits in both tests of binaural integration - dichotic digits and SSW. Bilateral changes are usually observed in lesions of the dominant hemisphere for the applied stimulus. In our study, bilateral deficits were confirmed as much in children with lesion in the left as in the right hemisphere. The poor bilateral performance may be attributed to the binaural integration task itself. This is because the subject is required to divide his attention between two sources of information simultaneously, imposing a substantial burden on the listener. The lower performance could be a reflection of the effort required for the task in detriment of the next task ${ }^{1,29}$. The proof of this effect is the finding of worse performance in SSW than in dichotic digits, verified by the increased amount of errors and in the change of default configuration, going from unilateral deficit in the dichotic digits test to bilateral deficit in the SSW, regardless of the hemisphere affected by the injury.

Evidence of change in the ability for selective attention could justify complaints, such as failure to understand instructions and explanations at unfavorable acoustic environments, below average academic performance, poor peer relations, among others aspects of communication, learning and behavior, in spite of the normal intellectual and cognitive abilities of patients in this study. Using the CAP, we were able to understand aspects of auditory processing in the evolution of children with stroke, confirming our expectations and the propositions of the Paediatric Stroke Working Group ${ }^{6}$.

Limitations of the study include the small number of participants, the broad range of ages in the acute phase of the disease, the pooling data of right and left hemisphere lesions in the same group, and lack of a children stroke control group with lesions not affecting the auditory pathway. Although the study assessed 13 stroke subjects, it is the only one for this 
topic to date and provide strong evidence that children after stroke of central auditory system could present auditory functional limitations that affect them in everyday life. These findings have implications for the clinical management of childhood stroke by recognizing that auditory processing impairments may limit the ability of the patient to recover from stroke and must be routinely evaluated. Further research is required to replicate and extend these findings.

In conclusion, this study of 13 children affected by unilateral stroke, with predominant involvement of the middle cerebral artery, mostly ischemic and cortico-subcortical, enabled the characterization of selective attention auditory ability.
In the dichotic non-verbal test, there was a compromised ability to direct attention, as demonstrated by the lateralization of stimuli and difficulty in directing attention in the directed steps, especially in the right condition. In the consonant-vowel test, patients made errors and inversions, being unable to effectively alter the focus of attention in relation to controls. In the binaural integration tests, dichotic digits and SSW, ipsilateral, contralateral and bilateral alterations were found depending on the characteristics of the lesion and the level of demand in the task.

Children with stroke showed impairments in the selective attention ability in activities that required separation and integration of verbal and non-verbal auditory information.

\section{References}

1. Kolk A, Ennok M, Laugesaar R, Kadoja ML, Talvik T. Long-term cognitive outcomes after pediatric stroke. Pediatr Neurol 2011;44:101-109.

2. Westmacott R, Askalan R, Macgregor D, Anderson P, DeVeber G. Cognitive outcome following unilateral arterial ischaemic stroke in childhood: effects of age at stroke and lesion location. Dev Med Child Neurol 2010;52:387-393.

3. Pavlovic J, Kaufmann K, Boltshauser E, et al. Neuropsychological problems after paediatrics stroke: two year follow-up of Swiss children. Neuropediatrics 2006;37:13-19.

4. Cnossen MH, Aarsen FK, Akker SLJ, et al. Paediatric arterial ischaemic stroke: functional outcome and risk factors. Dev Med Child Neurol 2010;52:394-399.

5. Braun KPJ, Bulder MMM, Chabrier S, et al. The course and outcome of unilateral intracranial artheriopathy in 79 children with ischaemic stroke. Brain 2008;132:544-557.

6. Paediatric Stroke Working Group. Stroke in childhood: clinical guidelines for diagnosis, management and rehabilitation. The Royal College of Physicians 2004;1:31-41.

7. Blom I, De Schryver ELLM, Kappele LJ, Rinkel GJE, Jennekens-Schinkel A, Peters ACB. Prognosis of haemorrhagic stroke in childhood: a longterm follow-up study. Dev Med Child Neurol 2003;45:233-239.

8. Hogan AM, Kirkham FJ, BChir MB, Isaacs EB. Intelligence after stroke in childhood: review of the literature and suggestions for future research. J Child Neurol 2000;15:325-332.

9. Ganesan V, Hogan A, Shack N, Gordon A, Isaacs E, Kirkham FJ. Outcome after ischemic stroke in children. Dev Med Child Neurol 2000;42:455-461.

10. Bellis TJ. Assessment and management of central auditory processing disorders in the educational setting: from science to practice. $2^{\text {nd }}$ ed. Clifton Park, New York: Delmar Learning; 2003.

11. Yavas M, Hernandorena CM, Lamprecht RR. Avaliação fonológica da criança: reeducação e terapia. Porto Alegre: Artmed, 2001.

12. Pereira LD, Schochat E. Processamento auditivo central: manual de avaliação. São Paulo: Lovise; 1997

13. Lemos SMA. Análise de sons não-verbais sobrepostos por escolares: influência dos distúrbios da comunicação e audição [dissertação de mestrado]. Universidade Federal de São Paulo, São Paulo, Brasil; 2000.

14. Tedesco MLF. Audiometria verbal: teste dicótico consoante-vogal em escolares de 7 a 12 anos de idade [dissertação de mestrado]. Universidade Federal de São Paulo, São Paulo, Brasil; 1995.

15. Sauer LO. Teste dicótico consoante-vogal e indivíduos de 8 a 12 anos de idade [monografia de especialização]. Universidade Federal de São Paulo, São Paulo, Brasil; 1997.

16. Moura-Ribeiro MVL, Ferreira LS, Montenegro MA, et al. Doença cerebrovascular na infância: aspectos clínicos em 42 casos. Arq Neuropsiquiatr 1999;57:594-598

17. Amlie-Lefond C, Sébire G, Fullerton HJ. Recent developments in childhood arterial ischaemic stroke. Lancet Neurol 2008;7:425-435.

18. Raju TNK, Nelson KB, Ferriero D, Lynch JK. Ischemic perinatal stroke: summary of workshop sponsored by the Institute of Child Health and Human Development and the National Institute of Neurological Disorders and Stroke. Pediatrics 2007;120:609-616.

19. Krleza JL, Duranovic V, Lujic L, et al. The burden of paediatric stroke and cerebrovascular disorders in Croatia. Int J Stroke 2009;4:390-394.

20. Bamiou DE, Sisodiya S, Musiek FE, Luxon LM. The role of interhemispheric pathway in hearing. Brain Res Rev 2007;56:170-182.

21. Crinion JT, Lambon-Ralph MA, Warburton EA, Howard D, Wise RJS Temporal lobe regions engaged during normal speech comprehension. Brain 2003;126:1193-1201.

22. Ortiz KZ, Pereira LD, Borges ACLC, Vilanova LCP. Verbal and non-verbal auditory processing: a comparative study. Iran Audiol 2003;2:52-60.

23. Bamiou DE, Musiek FE, Luxon LM. The insula (Island of Reil) and its role in auditory processing: literature review. Brain Res Rev 2003:42:143-154.

24. Isaacs E,Christie D,Vargha-Khadem F,Mishkin M. Effects of hemisphere side of injury, and presence of seizure disorder on functional ear and hand asymmetries in hemiplegic children. Neuropsychologia 1996;34:127-137.

25. Brizzolara D, Pecini C, Brovedani P, Ferretti G, Cipriani P, Cioni G. Timing and type of congenital brain lesion determine different patterns of language lateralization in hemiplegic children. Neuropsychologia 2002;40:620-632.

26. Chilosi AM, Cipriani P, Pecini C, et al. Acquired focal brain lesions in childhood: effects on development and reorganization of language. Brain Lang 2008;106:211-225.

27. Sidtis JJ. Predicting brain organization from dichotic listening performance: cortical and subcortical functional asymmetries contribute to perceptual asymmetries. Brain Lang 1982;17:287-300.

28. Wexler BE, Halwes T. Dichotic listening tests in studying brain-behavior relationships. Neuropsychologia 1985;23:545-559.

29. Mackersie CL, Boothroyd A, Prida T. Use of simultaneous sentence perception test to enhance sensitivity to ease of listening. J Speech Lang Hear Res 2000;43:675-682. 